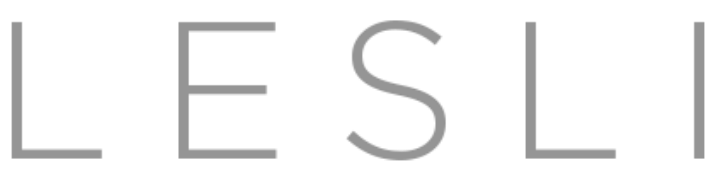

Linguistic Evidence in Security, Law and Intelligence

Volume 1, No. 1 (2013) | ISSN 2327-5596 (online) | DOI 10.5195/lesli.2013.4 | http://lesli-journal.org

\title{
False Confessions and the Use of Incriminating Evidence
}

\section{Tim Cole $\mathrm{PhD}$}

Associate Professor/Program Director, Relational Communication, College of Communication, DePaul University, USA

tcole@depaul.edu

\section{JC Bruno Teboul PhD}

Professor and Associate Dean, College of Communication, DePaul University, USA

jteboul@depaul.edu

\section{David E Zulawski}

Senior Partner and Co-Founder, Wicklander-Zulawski \& Associates, USA

DZulawski@w-Z.com

\section{Douglas E Wicklander}

Senior Partner and Co-Founder, Wicklander-Zulawski \& Associates, USA

DWicklander@W-Z.com

\section{Shane G Sturman}

Senior Partner, Wicklander-Zulawski \& Associates, USA

SSturman@w-Z.com

\begin{abstract}
To date, few experimental studies have looked at the factors that influence people's willingness to confess to something they did not do. One widely cited experiment on the topic (i.e., Kassin \& Kiechel, 1996) has suggested that false confessions are easy to obtain and that the use of false incriminating evidence increases the likelihood of obtaining one. The present research attempted to replicate Kassin and Kiechel's (1996) work using a different experimental task. In the present experiment, unlike Kassin and Kiechel's (1996) study, the participants were completely certain that they were not responsible for what had happened, thereby providing a different context for testing the idea that false incriminating evidence increases the likelihood of obtaining a false confession. The results are discussed with respect to factors that may or may not increase individuals' willingness to offer a false admission of guilt.
\end{abstract}

Keywords: false confession, subjective awareness, incriminating evidence, interrogation techniques

\section{$(\mathrm{cc}) \mathrm{Br}_{\mathrm{Br}}$}

Articles in this journal are licensed under a Creative Commons Attribution 3.0 United States License.

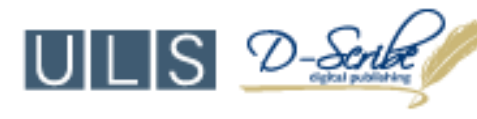

This journal is published by the University Library System, University of Pittsburgh as part of its D-Scribe

Digital Publishing Program and is cosponsored by the University of Pittsburgh Press. 


\section{False Confessions and the Use of Incriminating Evidence}

Confessions play a critical role in our system of justice. Self-incriminations are often the determining factor influencing case outcomes in both the private and public sector (Kassin, 1997). However, confessions, like many other aspects of our justice system, can be fraught with error. At worst, false confessions have been used to convict and punish the innocent (Leo \& Ofshe, 1998).

Empirical research, which would help shed light on the issue of false confessions, is difficult to conduct. Meaningful results require that individuals be placed in a variety of situations where people are interrogated for crimes they did and did not commit. Placing people in such situations is generally unethical, which greatly limits the type of research that scholars can conduct. As a result, little relevant experimental research has been done on interrogation techniques and false confessions.

One notable exception was a cleverly designed study conducted by Kassin and Kiechel (1996). In their study, Kassin and Kiechel (1996) asked students to participate in a computer-based reaction time test. During the experiment, the participants were asked to type letters on a keyboard as they were spoken aloud. The participants were instructed NOT to hit the "ALT" key during the task or else the computer would crash and all of the data would be lost. Unbeknownst to the participants, approximately a minute into the typing test, the computer was designed to crash. The experimenter immediately accused the participants of hitting the "ALT" key. When the participants offered an initial denial, the experimenter examined the keyboard and claimed that the data from the study had indeed been lost. The experimenter again (falsely) accused each participant of hitting the "ALT" key: "Did you hit the 'ALT' key?” (Kassin \& Kiechel, 1996, p. 126).

In addition, the researchers manipulated two independent variables during the experiment: vulnerability and the use of false evidence. Vulnerability was manipulated by varying the speed of the typing task - a slow paced condition (43 letters per minute) versus a fast-paced condition (67 letters per minute). False evidence was manipulated in two ways - either by having a confederate student provide a false eyewitness account of the participant hitting the "ALT" key or the confederate claimed not to see what happened. The dependent outcome, among other things, was the willingness of the participants to sign a false confession stating that they had accidentally hit the "ALT" key during the reaction time test. Across all conditions, $69 \%$ of the participants signed a false confession. Participants were least likely to sign a false confession in the slow-paced, no false witness condition (35\%) and they were the most likely to sign an admission of guilt in the fast-paced, false witness condition (100\%).

Kassin and Kiechel (1996) when discussing their results reported the following:

"The present study provides strong initial support for the provocative notion that the presentation of false incriminating evidence - an interrogation ploy that is common among the police and sanctioned by many courts - can induce people to internalize blame for outcomes they did not produce. These results provide an initial basis for challenging the evidentiary validity of confessions produced by this technique." ( $p$. 127).

The influence of Kassin and Kiechel's (1996) study is hard to overstate. Their study was published in a prestigious academic journal (Psychological Science) and it has been widely cited over the years (e.g., Hoeffel, 2002; Lassiter, 2002; Meares \& Harcourt, 2000; Nadler, 2002; Schacter, 1999, Weisselberg, 1998; etc.). Not only has this study been extensively cited across a variety of academic disciplines (psychology, law, criminal behavior), but also the findings have been called "amazing" and "provocative" (Agar, 1999, p. 27, Kassin, 1997, p. 227). Kassin and Kiechel's (1996) results have even made their way into college lectures, industry-based seminars, textbooks, as well 
as the popular press (Psychology Today, Perina, 2003; New York Times Upfront; Smith 2003; The Olympian, Shannon, 1996).

In addition to being widely cited, Kassin and Kiechel's (1996) work has been replicated on at least three other occasions (see, Forrest et al., 2002; Horselenberg et al., 2003; Redlich \& Goodman, 2003). These replications all made use of the same general technique - a typing test where a computer is designed to crash and the participants are subsequently accused of hitting a key they were asked not to hit. Overall, these replications lend further support to Kassin and Kiechel's (1996) main claim - that false confessions can be easily obtained. Between $61 \%$ and $82 \%$ of the participants in these studies took responsibility for an action they did not commit.

While Kassin and Kiechel's (1996) original study tends to be viewed as providing provocative support for the idea that false confessions can be obtained through the mere use of false evidence, we believe that there are several underlying issues that warrant further investigation and debate. Specifically, we believe that there are two interrelated problems associated with Kassin and Kiechel's (1996) original study that cast doubt on some of the claims being made. We believe that vulnerability was inadequately operationalized and as such the role that subjective awareness may have played in their experiment was not emphasized. We believe that these issues have led to problems with the way that Kassin and Kiechel's (1996) results are often cited.

To begin with, we believe that there are problems with Kassin and Kiechel's (1996) operationalization and discussion of vulnerability. In their methods section, Kassin and Kiechel (1996) define vulnerability as participants' "subjective certainty concerning their own innocence" (p. 126). In other words, are the participants aware of what they may or may not have done? To manipulate levels of uncertainty/vulnerability, Kassin and Kiechel (1996) varied the pace of the typing task in the low vulnerability condition from 43 letters per minute to 67 letters per minute in the high vulnerability condition. Their manipulation check involved examining the number of typing errors that occurred across these two conditions. While this manipulation check showed that people made more typing errors when typing faster, it does not necessary mean that people were more uncertain about their culpability in the highly vulnerable condition. The manipulation check did not address the participants' subjective awareness of their actions.

We believe that if Kassin and Kiechel (1996) had assessed the participants' subjective uncertainty, rather than merely observe typing errors - they would have found that the participants most likely exhibited a fairly high degree of uncertainty/vulnerability even in the low vulnerable (slow typing) condition. Accidentally hitting the wrong key during a typing test, for most people, seems fairly plausible. Accordingly, we believe that a fairly high level of uncertainty/vulnerability was present throughout all of their experimental conditions. This claim has important implications which will be addressed shortly.

Not only do we believe that there were problems with Kassin and Kiechel's (1996) operationalization of vulnerability, but we also think that they did not adequately address this issue in the discussion of their findings. For the most part, their discussion focuses on the issue of false evidence. Kassin and Kiechel (1996) call their findings about the use of false evidence "provocative" and claim that the results provide a basis for challenging the use of this technique by law enforcement (p. 127). With respect to the issue of vulnerability/uncertainty, this variable is mentioned only in passing - as a limitation of the study - that the typing task involved an "unconscious act of negligence, not an act involving explicit criminal intent” (Kassin \& Kiechel, 1996, p. 127).

We believe, however, that the participants' level of uncertainty about their culpability is the decisive factor underlying the findings obtained (also see Freyd, 1996; Gleaves \& Freyd, 1997). Simply put, false confessions can occur when people are falsely accused of an action AND they have no awareness or recollection of what they may have done. Essentially, we believe that the results obtained by Kassin and Kiechel (1996) are most likely due to an interaction between the use of false evidence and the participants' lack of awareness about whether or not they 
struck the "ALT" key while typing. False evidence is not necessarily a problem in and of itself; rather it can be highly problematic when people lack awareness or knowledge of their culpability. Essentially, we believe that even in Kassin and Kiechel's (1996) low vulnerable condition, the participants were still highly prone to giving a false confession due to the inherent uncertainty underlying the typing task used.

Because of the problems identified above, we believe that the results of Kassin and Kiechel's (1996) study are often overstated or cited out of their appropriate context (also see, Freyd, 1996; Gleaves \& Freyd, 1997). While not always the case (see, Kassin et al., 2003; Wood, 2000), in many instances the claims made about the findings focus solely on the interrogation strategy used to obtain a false confession rather than the context in which the strategy was used.

For instance, when discussing Kassin and Kiechel's (1996) study, Loftus (1997a) states that, "merely [italics added] claiming to have seen a person do something can lead that person to make a false confession of wrongdoing" (p. 75). In another article, Loftus (1997b) notes that these "findings show powerfully that false incriminating evidence can lead people to accept guilt for a crime they did not commit” (p. 84). Lassiter et al., (2002) also describes Kassin and Kiechel's (1996) study by focusing on the interrogation technique used rather than the psychological context in which it occurred when they state, "However, such third-degree intimidation has been replaced by non-assaultive psychological manipulation that is not always recognized as coercive but, as research has shown, can nonetheless lead to false admissions of guilt" (p. 871). Or as noted by Hoffman et al., (2001), "Similarly, Kassin and Kiechel (1996) found that presenting people with false incriminating evidence can lead them to confess to an act they did not commit and to internalize the confession and, perhaps, confabulate details in memory" (p. 403). Likewise, Koriat et al., (2000) note that, "Innocent subjects who initially denied the charge of damaging a computer, tended to admit that charge, express guilt, and provide confabulatory details when a confederate said that she had seen them perform the action" (p. 507). And Garven at el., (1988) claim that "Kassin and Kiechel (1996) found that college students were substantially more likely to make a false confession to wrongdoing when a "witness" claimed to have seen the act" (p. 356). Finally, when discussing a rape case in a local newspaper article, Loftus is quoted as saying "a scholarly journal this month reported on an experiment in which 90 percent of subjects would confess if you tell them someone else saw them do it" - an apparent reference to Kassin and Kiechel's (1996) study (Shannon, 1996 cited in Gleaves \& Freyd, 1997, p. 993; also see, Freyd, 1996).

As this brief review illustrates, citations of Kassin and Kiechel's (1996) experiment often focus on the interrogation strategy used to create a false confession, rather than referring to the interplay between interrogation techniques and the context in which such strategies may be problematic. Consistent with our claim is the fact that we have not been able to find a single instance where their study is used to make claims solely about the context in which a false confession might be produced - that being situations where people lack knowledge of their actions. This is especially interestingly in light of the fact that approximately 50\% of the participants in Kassin and Kiechel's (1996) study confessed without ever being confronted with the use of false evidence. By comparison, Kassin and Kiechel's (1996) study is often used when making claims about the problematic nature of using false evidence without linking those results to any context whatsoever. In fact, to read the literature, it is possible to come to the conclusion that the use of false evidence is highly questionable, regardless of how and when it is used. This conclusion is concerning, given the possibility that the situational context (subjective uncertainty) may be the decisive factor underlying Kassin and Kiechel's (1996) findings.

There have been real world consequences associated with Kassin and Kiechel's (1996) research. Calls have been made to challenge or regulate the use of false evidence on the basis of their study (Conti, 1999; Kassin \& Kiechel, 1996; Lassiter et al., 2001). Experienced practitioners, on the other hand, claim that the use of false evidence is often very useful when trying to solve actual crimes in the real world. Clearly, more research needs to be done in 
order to have a better understanding of how and when the use of false evidence may or may not be more likely to result in a false confession.

In summary, we believe that "extraordinary claims require extraordinary evidence" (Carl Sagan). So while Kassin and Kiechel's (1996) work is used to make provocative claims, we feel the evidence presented to date falls short. Accordingly, we replicated Kassin and Kiechel's (1996) study in an attempt to address the following research question: Is it easy to obtain false confessions when individuals are subjectively certain of their actions? With this in mind, we replicated Kassin and Kiechel's research in a context where the consequences are low (why not confess?), but where people are certain that they are not at fault ("I didn't do it.").

\section{Method}

\section{Overview}

The present study was designed to examine if the use of false evidence can result in false confessions in a context where the consequences for confessing are low, but subjective certainty about one's actions is high. We used methods similar to those used in prior research - making accusations of wrongdoing and presenting individuals with false evidence - but we conducted our research using a different task. Rather than using a typing test, we wrongly accused the participants in our study of breaking a lamp.

\section{Participants}

Fifty-five individuals participated in this study, which was conducted at a large, urban, private university. Twenty men $(36 \%)$ and thirty-five women $(64 \%)$ took part in the experiment and their median age was twenty-one $(\min =$ 18 , $\max =24)$. All participants received a $\$ 10$ reward for their involvement in the study.

\section{Procedure}

Participants were recruited through flyers posted on campus and handed out in large introductory-level liberal arts and sciences courses. The flyers asked potential participants to contact the lead investigator via email and set up an individual appointment to participate in the study. Through the recruitment process, the participants were led to believe that they would be filling out a survey and subsequently discussing some of their answers with one of the primary investigators.

When each participant arrived for his/her appointment, he/she met with one of the investigators in the researcher's office on campus. Each participant was told that he/she would be filling out a survey about "close relationships" and that when finished he/she would be discussing some of his/her answers with the researcher. The participants were then taken to a room down the hallway where they were instructed to fill out the questionnaire in private (for this task, a thirty-six item attachment style questionnaire was used; Brennan, Clark, \& Shaver, 1998). The researcher led each student to the research room, handed them the questionnaire, and told each participant to report back to the researcher when the survey was completed. The researcher did not enter the room with the student at that time. In each instance the researcher left the door to the research room ajar by a couple of inches. Inside the office there was a conference table and chairs. Placed on the table before the participant's arrival was a broken Green Banker's Desk Lamp. The lamp was lying on its side and bits of broken glass varying in size and shape were spread around the lamp.

When the participants finished the survey and stepped out to get the researcher, the researcher met them saying, "I want to go over some of your answers with you." The researcher led each student back into the room expressing surprise at finding the broken lamp, and asked each participant directly, "Did you knock over the lamp?" Upon 
receiving an initial denial, the researcher again asked the student if he/she broke the lamp - "Are you sure?" At this point, half of the participants were randomly confronted with incriminating false evidence provided by a confederate. In the false evidence condition $(n=26)$, the department's administrative assistant, whose desk was located directly outside of the research office said, "I heard the lamp break while you were in there." The researcher then looked at the participant and asked again, "Are you sure you didn't break the lamp?" In the no false evidence condition $(n=29)$, the researcher simply made the last accusation while the administrative assistant remained silent. The participants' verbal responses to these accusations were noted and served as the dependent outcome.

After the last accusation was made, the researcher ended the experiment and began debriefing the participants. During the debriefing process the researcher explained the true purpose of the experiment and probed the participants about their experience. Among other things, participants were asked about their perceptions of the situation, what they thought about the task, and why they responded the way they did. Overall, the participants were convinced someone else had broken the lamp and that they were being falsely accused of doing so. All but three students felt that the situation was "real" and that the researcher was accusing them of breaking the lamp (the responses from those three participants were excluded from the study, although their answers did not deviate from those reported below). The participants all said that they were aware of the lamp being broken before answering the question and they were all certain that they had not been responsible for breaking it. When asked why they were so certain - the participants said that "I saw the lamp when I sat down," "I didn't hear the lamp break," "I would have known if the lamp had been broke while I was in the room," etc. The participants believed that someone else, maybe the student before them or the cleaning staff, must have knocked the lamp over. In the false evidence condition, the participants were troubled and concerned that the administrative assistant had heard the lamp break while they were in the room, but knew that they were not responsible. Most participants reported feeling stress and anxiety when being wrongly accused of breaking the lamp, but all of the participants reported that the experiment was fun and interesting after it was over. Finally, the participants were asked what they thought might happen to them if they admitted to breaking the lamp. Only a few students mentioned that "maybe, you'd try to make me pay for it," but most said "nothing, I guess," etc. At the end of the debriefing session, the participants were instructed not to talk about the experiment with any one else, and all were given $\$ 10$ for their participation.

\section{Results}

The participants verbal responses were analyzed and coded for false admissions of blame (e.g., "maybe," "I might have," etc.) or denials of guilt (e.g., "no," "I didn’t do it," etc.) Not a single participant confessed to breaking the lamp or even offered a response that suggested that they might be somehow responsible. Rather, only strong protestations of innocence were obtained. Participants strongly and explicitly denied breaking the lamp, even when presented with incriminating false evidence. Statements such as "no," "I didn't do it," "it was broken before," were commonly used by the participants. The follow-up accusation, "Are you sure?" only produced stronger denials, such as "I'm positive I didn't' do it," "Yes, I'm sure," "It was already broken," or "It was like that when I came in."

\section{Discussion}

The results of the current study are at odds with Kassin and Kiechel's (1996) study and three subsequent replications (Forrest et al., 2002; Horselenberg et al., 2003; Redlich \& Goodman, 2003). In those studies, the vast majority of the participants accepted blame for something they did not do. Despite our best effort to obtain confessions using similar methods, we could not obtain a single false confession. The prior studies all relied on a typing test and tried to obtain admissions of guilt by wrongly accusing the participants of accidentally hitting a key they were explicitly told to avoid. We, on the other hand, placed the students in a room with a broken lamp and subsequently accused them of breaking it. All of the studies, including the present one, made use of false incriminating evidence when 
trying to obtain a false admission of guilt. Again, in the prior studies, most of the participants confessed - in our study, no one did.

We believe that the disparity between our results and prior research stems from the difference in the level of uncertainty (subjective awareness about one's behavior) inherent in breaking a lamp versus hitting the wrong key during a typing test. The participants in our study were certain they did not break the lamp, and even when confronted with false evidence they did not confess. We believe that the participants in the prior typing-test studies were more uncertain of their actual culpability, and as such they were more willing to offer an admission of guilt. Accordingly, we argue that subjective knowledge is most likely the decisive factor underlying people's willingness to offer a false confession in the experimental research that has been reported to date.

We hope that the present study will generate more research and debate about false confessions, the situations in which they are likely to occur, and how to best prevent them from happening. We also hope that our research will lead to more careful citation of prior work on the topic. As noted earlier, Kassin and Kiechel's (1996) research is often used to make the point that false confessions are easy to obtain, especially when false evidence is brought to bear. We believe that the real message underlying Kassin and Kiechel's (1996) work is not about the problems underlying the use of false evidence, but the problematic nature of interrogating individuals who may lack subjective awareness of their behavior - using false evidence tends to make a bad situation worse.

While we think that our study helps raise the possibility that subjective awareness of one's own behavior may be the decisive factor underlying the false confessions obtained in prior experimental research, the present study is not without its limitations. Our situational task, while designed to involve a high level of subjective awareness (like most crimes) does not necessarily mean that our results apply to interrogations in the real world. In real life, interrogations involve a lot more than asking accusatory questions for a very brief period of time. As such, our results may only pertain to situations similar to the one used in our study. Perhaps if we had spent more time questioning our participants and had been able to employ more interrogation techniques we might have obtained at least one false confession. This limit notwithstanding, we do think that our work can help evaluate interrogation practices. We believe that our work helps to highlight the important role of subjective uncertainty in the prior experimental studies reported to date. As such, we believe that at the very least, practitioners should exercise extreme caution when questioning individuals who may lack knowledge or awareness of their own behavior.

In summary, investigators need to use interrogation techniques to question suspects in an attempt to resolve crimes in a democratic society. And scholars have the difficult task of examining the interrogative process to ensure that individuals' constitutional rights against self-incrimination are protected, while also helping to identify interrogation practices that are effective. More debate, research, and discussion will be needed to help resolve these complex issues. 


\section{References}

Agar, J. R. (1999). The admissibility of false confession expert testimony. The Army Lawyer, August, 2642.

Brennan, K. A., Clark, C. L., \& Shaver, P. R. (1998). Self-report measures of adult attachment: An integrative overview. In J. A. Simpson \& W. S. Rholes (Eds.), Attachment theory and close relationship (pp. 46-76). New York: Guilford Press.

Conti, R. P. (1999). The psychology of false confessions. Journal of Credibility Assessment and Witness Psychology, 2, 14-36.

Forrest, K, D., Wadkins, T. A.., \& Miller, R. L. (2002). The role of preexisting stress on false confessions: An empirical study. Journal of Credibility Assessment and Witness Psychology, 3, 23-45.

Freyd, J. J. (1996). The science of memory: Apply with caution. Traumatic StressPoints, 10, $1 \& 8$.

Garven, S., Wood, J.M., Malpass, R.S., \& Shaw, J.S. (1998). More than suggestion: The effect of interviewing techniques from the McMartin Preschool case. Journal of Applied Psychology, 83, 347-359.

Gleaves, D. H., \& Freyd, J. J. (1997). Questioning additional claims abut the false memory syndrome epidemic. American Psychologist, 52, 993-994.

Hoeffel, J. C. (2002). The sixth amendment's lost clause: Unearthing compulsory process. Wisconsin Law Review, 1275-1361.

Hoffman, H. G., Granhag, P. A., Kwong See, S. T., \& Loftus, E. F. (2001). Social influences on reality monitoring decisions. Memory and Cognition, 29, 394-404.

Honts, C. R. (1996). Criterion development and validity of the CQT in field application. The Journal of General Psychology, 123, 309-324.

Horselenberg, R., Merckelbach, H., Josephs, S. (2003). Individual differences and false confessions: A conceptual replication of Kassin and Kiechel. Psychology, Crime \& Law, 9, 1-8.

Kassin, S. M. (1997). The psychology of confession evidence. American Psychologist, 52, 221-233.

Kassin, S. M., \& Kiechel, K. L. (1996). The social psychology of false confessions: Compliance, internalization, and confabulation. Psychological Science, 7, 125-128.

Kassin, S. M., Goldstein, C. C., \& Savitsky, K. (2003). Behavioral confirmation in the interrogation room: On the dangers of presuming guilt. Law and Human Behavior, 27, 187-203.

Lassiter, G. D. (2002). Illusory causation in the courtroom. Current Directions in Psychological Science, 11, 204-208.

Lassiter, G. D., Geers, A. L., Handley, I. M., Weiland, P. E., \& Munhall, P. J. (2002). Videotaped interrogations and confessions: A simple change in camera perspective alters verdicts in simulated trials. Journal of Applied Psychology, 87, 867-874.

Lassiter, G. D., Geers, A. L., Munhall, P. J., Handley, I. M., \& Beers, M. J. (2001). Videotaped confessions: Is guilt in the eye of the camera? In M. P. Zanna (Ed.), Advances in experimental social psychology, (Vol. 33, pp. 189-254). New York: Academic Press.

Leo, R. A., \& Ofshe, R. J. (1998). The consequences of false confessions: Deprivations of liberty and 
miscarriages of justice in the age of psychological interrogation. Journal of Criminal Law and Criminology, 88, 429-496.

Loftus, E. F. (1997a). Creating false memories. Scientific American, 277, 70-75.

Loftus, E. F. (1997b). Creating childhood memories. Applied Cognitive Psychology, 11, 75-86.

Meares, T. L., \& Harcourt, B. E. (2000). Supreme Court Review: Transparent adjudication and social science research in constitutional criminal procedure. The Journal of Criminal Law and Criminology, 90, 733-798.

Nadler, J. (2002). No need to shout: Bus sweeps and the psychology of coercion. The Supreme Court Review, 153, 1-58.

Perina, A. (March/April, 2003). "I confess:" Why would an innocent person profess guilt? Psychology Today, 11-12.

Redlich, A.D., \& Goodman, G.S. (2003). Taking responsibility for an act not committed: The influence of age and suggestibility. Law and Human Behavior, 27, 141-156.

Schacter, D. L. (1999). The seven sins of memory: Insights from psychology and cognitive neuroscience. American Psychologist, 54, 182-203.

Smith, P. (Sep. 1, 2003). Why would they falsely confess? New York Times Upfront, 136, 11.

Weisselberg, C. D. (1998). Saving Miranda. Cornell Law Review, 84, 109-192.

Wood, W. (2000). Attitude change: Persuasion and social influence. Annual Review of Psychology, 50, 539-570. 